\title{
Corrigendum: Effect of Underlying Renal Disease on Nutritional and Metabolic Profile of Older Adults with Reduced Renal Function
}

\author{
Silvia Lai ${ }^{1 *}$, Maria Ida Amabile', Silvia Altieri ${ }^{2}$, Daniela Mastroluca ${ }^{3}$, Carlo Lai ${ }^{4}$, \\ Paola Aceto ${ }^{5}$, Massimiliano Crudo $^{6}$, Anna Rita D'Angelo ${ }^{7}$, Maurizio Muscaritoli ${ }^{1}$ \\ and Alessio Molfino ${ }^{1}$
}

\begin{abstract}
'Department of Clinical Medicine, Sapienza University of Rome, Rome, Italy, ${ }^{2}$ Department of Clinical and Molecular Medicine, Sapienza University of Rome, UOC Nephrology, Sant'Andrea Hospital, Rome, Italy, ${ }^{3}$ Nephrology and Dialysis Unit, Hospital ICOT Latina, Sapienza University of Rome, Rome, Italy, ${ }^{4}$ Department of Dynamic and Clinic Psychology, Sapienza University of Rome, Rome, Italy, ${ }^{5}$ Department of Anesthesiology and Intensive Care, Catholic University of Sacred Heart Rome, Rome, Italy, ${ }^{6}$ Software House INTECS S.p.A., Rome, Italy, ${ }^{7}$ Department of Obstetrical-Gynecological Sciences and Urologic Sciences, Sapienza University of Rome, Rome, Italy
\end{abstract}

Keywords: older adults, chronic kidney disease, cardiovascular disease, inflammation, weight loss

OPEN ACCESS

Edited by:

Meghit Boumediene

Khaled, University of

Sidi-Bel-Abbès, Algeria

Reviewed by:

Mustapha Diaf,

University of Sidi-Bel-

Abbès, Algeria

${ }^{*}$ Correspondence:

Silvia Lai

silvia.lai@uniroma1.it

Specialty section:

This article was submitted

to Clinical Nutrition,

a section of the journal

Frontiers in Nutrition

Received: 07 April 2017 Accepted: 11 September 2017

Published: 04 October 2017

Citation:

Lai S, Amabile MI, Altieri S,

Mastroluca D, Lai C, Aceto $P$,

Crudo M, D'Angelo $A R$, Muscaritoli $M$ and Molfino A (2017) Corrigendum: Effect of Underlying Renal Disease

on Nutritional and Metabolic

Profile of Older Adults with

Reduced Renal Function.

Front. Nutr. 4:44.

doi: 10.3389/fnut.2017.00044

\section{A corrigendum on}

Effect of Underlying Renal Disease on Nutritional and Metabolic Profile of Older Adults with Reduced Renal Function

by Lai S, Amabile MI, Altieri S, Mastroluca D, Lai C, Aceto P, et al. (2017). Front. Nutr. 4, 4. doi:10.3389/fnut.2017.00004

In the original article, there was an error, in particular, in the results section of the Abstract:

Results: A total of 76 patients were enrolled. Group A ( $n=39$, M: 24, F: 15$)$ showed greater BWL with a significant reduction of 25 -hydroxyvitamin $\mathrm{D}$, transferrin, cholinesterase, albumin, and LVMI with respect to Group B ( $p<0.01)$. Conversely, Group B ( $n=37, \mathrm{M}: 23$, F: 14$)$ showed significantly increased intact parathyroid hormone, total cholesterol, low-density lipoprotein, triglycerides, and C-reactive protein when compared to Group A $(p<0.05)$.

A correction has been made in the results section of the Abstract.

Results: A total of 76 patients were enrolled. Group A ( $n=39$, M: 24, F: 15) showed greater BWL with a significant reduction of 25-hydroxyvitamin $\mathrm{D}$, transferrin, cholinesterase, albumin, and greater LVMI with respect to Group B ( $n=37, \mathrm{M}: 23, \mathrm{~F}: 14)(p<0.01)$. In addition, Group A showed significantly increased intact parathyroid hormone, total cholesterol, low-density lipoprotein, triglycerides, and C-reactive protein when compared to Group B $(p<0.05)$.

The authors declare that this error, present only in the abstract, does not change the scientific conclusions of the article in any way.

Conflict of Interest Statement: The authors declare that the research was conducted in the absence of any commercial or financial relationships that could be construed as a potential conflict of interest.

The reviewer MD and handling editor declared their shared affiliation.

Copyright $\odot 2017$ Lai, Amabile, Altieri, Mastroluca, Lai, Aceto, Crudo, D’Angelo, Muscaritoli and Molfino. This is an open-access article distributed under the terms of the Creative Commons Attribution License (CC BY). The use, distribution or reproduction in other forums is permitted, provided the original author(s) or licensor are credited and that the original publication in this journal is cited, in accordance with accepted academic practice. No use, distribution or reproduction is permitted which does not comply with these terms. 